\title{
Impact of Emotional Contagion on Work Performance of Employees
}

\author{
E. M. H. L. Ekanayake ${ }^{1}$ and T. D. Weerasinghe ${ }^{2}$ \\ ${ }^{1}$ Assistant Lecturer, Department of Human Resources Management, Faculty of \\ Commerce and Management Studies, University of Kelaniya, Sri Lanka \\ ${ }^{2}$ Senior Lecturer, Department of Human Resources Management, Faculty of \\ Commerce and Management Studies, University of Kelaniya, Sri Lanka \\ ${ }^{1}$ harshikandy94@gmail.com, ${ }^{2}$ dananjaya@kln.ac.lk
}

\begin{abstract}
People possess variety of emotions. In spite of the effectiveness and the productiveness, they capture others' emotions and moods habitually. It spreads as if a virus among them. Employees serve as the life-blood of any organization that ensures the health at the workplace. Thus, every organization strives to enhance and nurture their work performance effectively and efficiently by carefully managing the factors that affect their performance. The previously mentioned habitual nature of catching others' emotions at work can have an impact on employees' performance. Hence, the purpose of this study was to assess the impact emotional contagion on individual work performance. The study is an explanatory, cross-sectional in nature. A standard questionnaire was administered among the participants of the sample, selected through convenience sampling technique, which encompasses 100 respondents who are in the age category of 18 years or above that who work organizations. The items in the questionnaire have been extracted from the standard measurement scales. Descriptive statistics, correlation and regression have been used to test the hypotheses and draw conclusions. Results revealed that there is a significant relationship between the emotional contagion and individual work performance. Further, a significant impact is found from emotional contagion on work performance; as R-square is $15.7 \%$ Thus, building on the findings, it is recommended that the individuals should spend more time with the ones who boost their morale while practicing the effective ways they can use to manage the impact of others' negative emotions and moods. Findings of the study would be beneficial for all the individuals, employees, managers, and for every organization that deploy humans at work to manage the emotions and moods productively in a way which they support their work performance.
\end{abstract}

Keywords: Emotional contagion, Cognitive contagion, Empathy, Emotional energy, Work performance

\section{Introduction}

As revealed by Domagalski (1999), the word 'contagion' has derived from a Latin word 'contagio' that means 'from touch' (as cited in Vijayalakshmi \& Bhattacharyya, 2011). The deceases can spread so quickly among the individuals as a result of touching each other and this is explained by the concept of contagion. The individuals are also catching not only the deceases, but also the behaviours, emotions, moods, and thoughts of others. It is obvious; people habitually catch others' ideas, thoughts, 
beliefs, behaviors, the way they talk, their moods and emotions quickly (Hancock et al, 2008). Totterdell et al., (1998) indicated that the moods of an individual member of the team can influence the mood of a team (as cited in Vijayalakshmi \& Bhattacharyya, 2011). Because of this nature of humans, it is easy to share a common understanding among the individuals by sharing the thoughts and ideas using words basically through frequent meetings, notices, speeches and discussions in an organization as creating such an understanding among the employees and aligned them with the common goals and objectives have become one of the major challenges that the organizations face nowadays. Felps et al., (2009) stated that most of the times the individuals in the same network are being affected directly by the similar thoughts, attitudes and behaviors of others (as cited in Im, Park \& Storey, 2013). This process of spreading or transferring the information, emotions, attitudes and behaviors among the individuals is commonly known as contagion (Ashkanasy \& Humphrey, 2011; Barsade, 2012; Monge \& Contractor, 2003).

The concept of contagion encompasses two dimensions. One is cognitive contagion and the other one is emotional contagion. Im, Park and Storey (2013) identified the cognitive contagion as a process of influencing the distribution of information, beliefs of knowledge among the individuals of groups through mindful or unconscious induction of cognitive fields. Apart from the behaviors, ideas and thoughts, sometimes people quickly capture and demonstrate others' emotions and the moods in the exact same way based on the atmosphere they are in since the emotions or the moods of a person transfer to another person within a few seconds. This phenomenon is known as the concept of emotional contagion (Barsade, Coutifaris, \& Pillemer, 2018). As mentioned above, the deceases are spreading speedily so as the emotions. That may be the reason why Philosopher Max Scheler has identified the emotional contagion as a process of 'emotional infection' (Coplan, 2006).

Most of the times, this transition of emotion happens in the work setting. It was stated that, the emotional displays of a leader at work directly related to the work attitudes and the work performance of the employees (Schaefer \& Palanski, 2013). Moving ahead as a tribe has become one of the major goals of the companies. Thus, organizations have a responsibility to manage the emotions of the workers successfully as when the employees hold positive emotions and moods they will transfer among each other effectively and efficiently which result in a favorable work environment and employee relationships within the organization whereas the negative moods and emotions on the other hand will transferred among the workers which will ultimately create an adversarial work environment in the organization. Moreover, according to Hsee et al., (1990) if a person has to spend too much of time with negative emotions such as fatigue, anger, there is a high level of possibility that one person end up feeling the same way (Vijayalakshmi \& Bhattacharyya, 2011). In a situation where a person walks in to a room with a joyful smile it will brightens up every individuals' day (Tsai et al., 2011). People would love to work in a happy work environment which makes them 
loyal to the company. When an employee possesses more positive thoughts about the organization and when he deals more pleasantly with others, the rest of the employees also tend to possess more positive thoughts about the company. On the other hand, in case of an employee possess more negative thoughts or the feelings towards the management and the organization. Dasborough (2006) indicated that the negative emotions are considered being a critical factor that affects the members' perception of leaders when compared to the positive emotions (as cited in Dasborough et al., 2009). This might affect the employees work performance positively or negatively. Schwartz (2012) has indicated that, he was being told the negativities about his workforce by an executive once and has influenced by that executive's negative feelings. As a result, he affected the rest of the employees in the office even more negatively as he is the boss. With this experience, he had mentioned the significance of emotional contagion at work with an article titled: "Emotional contagion can take down your whole team".

Considering the nature, the emotional contagion assumed to be a significant factor that can have an impact of employees work performance. Thus, the current study also focuses on the employees' performance as well since every organization's long-term survival is depending on their workers' work performance. Empirical evidence has suggested that, other than the financial resources, the human resources main factor that possesses the capability of obtaining the competitive advantage. In general, the performance depends on a large number of factors (Dobre, 2013).
Thus, their performance should be considered with those factors, which enhance of decrease their performance. Every employee is expected to perform effectively and efficiently in order to achieve the organizational goals and objectives (Kumari \& Sangwan, 2015) as performance has become the key in nurturing the organizational productivity whereas the productivity has been considered as critical in achieving the organizational success (Frimpong \& Agyekum, 2018). Other than the productivity, the organizations also can enhance the customer satisfaction, organizational development and growth with the well performed employees (Pradhan \& Jena, 2017).

Keeping the significance of the concept of emotional contagion which has taken a rare attention, the study has focused to identify the extent to which the process of transferring or moving the emotions among individuals' impact on their work performance

\section{Research Context}

Emotional contagion cannot be confined to an industry or to a company as it is common for all humans. Previous studies relating to the emotional contagion has emphasized that the humans are catching others' moods and emotions habitually, but further studies and cross validations are needed. The major focus of the present study is to assess its impact, and to bring a valuable insight to the work environment as this can affect the employees' work performance. As such, keeping in mind that the phenomenon of emotional contagion is common for all the individuals, the population of the current research study encompasses the employees who belong to the age group of 18 years or more than that. Hence, it 
can be stated that in here, the population is unknown to the researcher.

\section{Problem Statement}

People catch others' emotions promptly and demonstrate the appropriate responses with a least amount of time. Spreading the positive emotions and the moods will be an advantage for the company as it affects favorably to the entire workforce's motivation and satisfaction. But in case if there are adverse or the negative emotions and the moods, this will lead the employees to experience a high level of stress along with negative emotions. Especially, the leaders' expressions, emotions and the moods affect negatively their follower.

Tony Schwartz, the president and CEO of 'Energy Project' developed a scientifically-based approach to nurture the individuals mentally, physically, emotionally, and spiritually. Based on that approach, Schwartz (2012) has mentioned from his real experience that, when the emotional contagion takes place, if the negativity spread among the employees, it deprives the energy and the enthusiasm of the team and the organization as a whole. It was stated that the emotions that the employees bring to the workplace are as important as the cognitive skills they possess. The negative emotions are spreading speedy than we think and they are considered being highly toxic.

Having considered the above-mentioned evidence, current study raises the following research problem:

What is the impact of emotional contagion on employee performance?

\section{Objectives of the Study}

\section{General Objective:}

- To assess the effect of emotional contagion on individual work performance of employees.

\section{Specific Objectives:}

- To discuss the importance of focus on emotional contagion for the organizations.

- To discuss the importance of ensuring productive work performance of individuals at work.

- To assess the relationship between emotional contagion and individual work performance of employees.

\section{Literature Review}

Companies strive harder to become successful in this work environment which is considered being highly competitive. Thus, they seek the best individuals for their organizations who can add a value (Dobre, 2013). They are expecting their employees to perform in an effective and efficient way when achieving the stated goals and objectives (Kumari \& Sangwan, 2015). Campbell et al. (1993) have defined the performance as what an organization hires a person to do and do it well (as cited in Kumari \& Sangwan, 2015). It basically involves the quality and the quantity aspects of the output produced by an individual, the attendance at work, accommodative and supportive nature and the appropriateness of the output in terms of timeliness (Shahzadi et al, 2014). The earlier studies have specifically indicated that the work performance is characterized by three major types of behaviors including one's technical behaviors, skills and adaptability and the 
interpersonal behaviors. These kind of behaviors generate the positive outcomes as if, productivity enhancement, customer satisfaction, organizational development, and growth (Pradhan \& Jena, 2017). Thus, in order to gain the aforesaid outcomes, every organization strive to obtain a talented pool of employees in order to achieve their predefined goals and objectives, while achieving the competitive advantage through producing quality products (Kumari \& Sangwan, 2015).

According to Vijayalakshmi and Bhattacharyya (2011), in the journey towards to achieve the said objectives the organizations nowadays move from individual-driven entities to synergistic collaboration concentrated systems and here the employees play a vital role in ensuring the organization's ability to achieve the said goals where it is even more significant to focus more on the factors that affect their performance directly such as emotions. Herein, the concept of emotions in a group environment is significant than ever before and as mentioned by Hatfield et al. (1994) the organizational achievements depend not only on an individual employee, but also it depends on the group as a whole. Empirical evidence proved that the emotions are spreading across these people and situations because as explained by Lin and Liang (2011), the emotions have become a vital part of humans' everyday life (as cited in Vijayalakshmi and Bhattacharyya, 2011).These emotional states of the individuals can be transferred to others through emotional contagion and leading them to experience the same emotion what they observed (Kramera et al, 2014). It is a powerful agent in shaping the moods of the people in various situations which involves both conscious and unconscious mechanisms (Bispo \& Paiva, 2009). Number of studies has indicated that the people are imitating others facial expressions (McIntosh, 2006). Thus, the emotional contagion has been identified as a basis of imitation and innovation (Gaba \& Meyer 2008; Lieberman \& Asaba 2006, as cited in Im, Park, \& Storey, 2013). People catch others' emotions and mimic them within 1000 milliseconds even in response to unconsciously presented faces (Dimberg, Thunberg, \& Elmehed, 2000 as cited in McIntosh, 2006). It was stated that the emotional contagion involves the speed imitation and a prompt activation with a feedback for mimicry. Empirical evidence has indicated that the people tend to imitate what they observe (Coplan, 2006).

The concept of emotional contagion process happens so quickly and even the person does not aware of this as it happens. This does not mean that people never understand the contagion when it occurs. But the process is outside of our own control (Coplan, 2006). Thus, it is significant to understand the role of facial mimicry in emotional contagion (Hatfield et al., 1992, as cited in McIntosh, 2006). During a conversation, people tend to imitate and coordinate their own emotions and movements automatically and continuously with the gestures, postures, facial expressions, and all the instrumental behaviors of others (Hatfield et al., 2009). Posed Faces Elicit Zygomatic which is known as the process that happens when the muscles pull the corners of the lips back where we can see it as a smile, automatically activate when people see happy faces around and the muscles use 
to wrinkle the brows in front of angry faces Dimberg, 1982, 1988; Hess et al., 1998 as cited in McIntosh, 2006). Furthermore, Omdahl and O'Donnell (1999) replicated Miller et al.'s (1988) findings and a study has conducted in a hospital regarding the level of emotional contagion of nurses, and it was found that the nurses who deals more with the patients' emotions are likely to experience an emotional exhaustion (Barsade et al, 2018).

\section{Empathy}

The concept of emotional contagion was born out in the area of psychology as it basically deals with the individuals' and their emotions along with a psychological process that assist to spread the emotions. It has been identified as a key factor that affects the different functional aspects of an organization (Vijayalakshmi \& Bhattacharyya, 2011). This special factor can be identified as a special form of empathy (Nummenmaa, Hirvonen, Parkkola \& Hietanen, 2008 as cited in Dasborough et al, 2009).

\section{Emotional Energy}

Scherer (1981) explained the concept of emotional energy which describes the intensity where the emotions are being expressed and communicated from one to another. This involves the factors as if the pitch range, pitch level, loudness and the tone of the tempo, relates to a person who speaks. It was stated that the extent to which a person uses a greater level of energy will lead to more contagion as it involves greater quantity of attention. For example, if a person expresses his aggressive bad temper will lead to a stronger contagion if it involves with high energy-expressions with his of his feelings (Barsade, 2002).

\section{Cognitive Contagion and Emotional Contagion}

Furthermore, most of the researches relating to the contagion have emphasized the cognitive aspect rather than the emotional aspect (Im, Park \& Storey, 2013). Barsade (2002) mentioned that the Cognitive Contagion as a process where the individuals or the groups affect the distribution of information, knowledge or the beliefs between others through conscious or unconscious induction of the cognitive fields. As explained by Elfenbein (2007), compared to cognitive contagion, the emotional contagion is a powerful tool to influence others' emotions, moods, and attitudes.

\section{Facial Feedback}

According to Darwin (2005), the feedback comes from the facial muscles considered being a highly critical factor as it affects intensely towards the emotional experience of people (as cited in Hatfield et al, 2009). Early stduies have revealed that most of the researchers have tested this facial feedbacks using a number of strategies to persuade individuals to accept emotional facial expressions where once the participants were required to embellish or strive to hide any emotional actions they possess and secondly they were tricked in to accept a number of facial expressions. Thirdly, they have prepared things where the participants will mimic the emotions and the facial expressions of others unconsciously. They were found that in all the three situations the individuals' emotional experiences were 
affected by the facial expressions they were adopting (Adelmann \& Zajonc, 1989; Matsumoto, 1987 as cited in Hatfield et al, 2009).

\section{Vocal Feedback}

A range of evidence supports the argument relates to the subjective emotional experiences of the individuals are being affected with the activation of feedback comes as a result of vocal mimicry (Duclos et al., 1989; Hatfield, Cacioppo \& Rapson, 1994; Hatfield et al., 1995; Zajonc, Murphy, \& Inglehart, 1989 as cited in Hatfield et al, 2009). According to the communication researchers' findings, the basic human emotions are linked with specific patterns of accent, the quality of vocals, rhythm, and pausing. Particularly, the sounds that are blissful had the characteristics of laughter where the sad sounds had the characteristics of crying. Love sounds had the qualities of romance or the soft whereas angry sounds had the qualities of low tones which are coming from the throat and finally the fearful sounds had a bunch of short and sharp cries and grasps. When it comes to the research findings, the participants' emotions were largely affected by the sounds the produced relating to the above five tapes of happiness, sadness, anger, love, and fear (Hatfield et al, 2009).

\section{Notional identifications relating to the current research study}

The theories relating to contagion has investigated and emphasized the spread of emotions, attitudes, behaviors, knowledge, and information among the individuals, teams, or firms in the similar social networks (Ashkanasy \& Humphrey, 2011; Barsade 2002; Monge \& Contractor 2003 as cited in Im, Park \&
Storey, 2013). Most of the theories relating to the emotional contagion suggested that the primitive emotional contagion urged by the degree to which a person's displayed emotions. A greater emotional display by the sender can create a greater emotional contagion in the receiver's point (Hennig-Thurau et al, 2006). In the concept of emotional contagion, the primitive emotional contagion is serving as the basic building block of the human interactions and it assists the mind reading where it enhances the capability of the humans of understanding others' emotions and moods (Hatfield et al, 2009).

\section{Primitive emotional contagion}

Various disciplines such as neuroscience, biology, social psychology, sociology, and life-span psychology have pointed out the concept of primitive emotional contagion as a critical factor in understanding the human behavior, cognition, and emotions (Hatfield et al, 2009). Hatfield et al., (1993) has provided the insight of Primitive Emotional Contagion which can be identified as a major contributing factor for the concept of emotional contagion. It has been defined as the propensity of an individual to automatically imitate and coordinate the expressions and vocalizations and the gestures and postures of another person and displaying most related emotions as a return and Hatfield et al., (1994) mentioned that it is involved with the receiver's unconscious emotive process when transfer of emotions from one to another (Bispo \& Paiva, 2009). Moreover, it was emphasized that the primitive emotional contagion involves three major stages in a sequential process. 


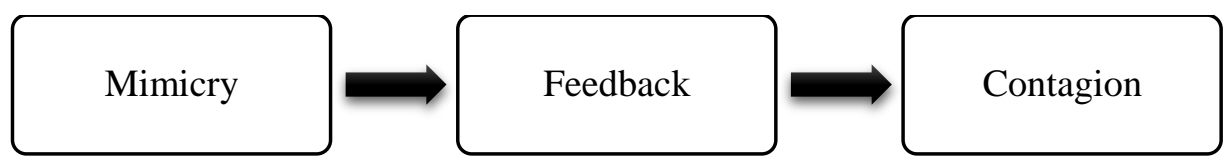

Figure 01: Stages of Primitive Emotional Contagion

Source: Authors (2020) based on Hatfield et al., (2014)

\section{Theory of Conscious Emotional Contagion}

According to Barsade (2002) unlike the primitive emotional contagion, the theory of conscious emotional contagion emphasize that the individuals compare their moods with each other and adopt the sender's emotions when it emerge appropriate (Hennig-Thurau et al, 2006). For an example without having appropriate information, when meeting a lawyer for the first time, the person first view the lawyer's emotional display and then change the emotions as a result. In addition, the conscious emotional contagion decided less by the extent to which the emotions display by the sender during the interactions such as frequency of smiling and by the genuineness of the emotions are displayed as if genuineness of the smile. In case of the sender's displayed emotions perceived to be fake in order to reduce the apparent uncertainty, the person would not interpret the emotions as adequate. Thus, it can be emphasized that the conscious emotional contagion is not occurring frequently (Hennig-Thurau et al, 2006).

\section{Affective Events Theory}

The Affective Events Theory explained by Weiss and Cropanzano (1996) emphasized that the work attitudes and the employees work performance are influenced by the emotional reactions occur from the daily work events (Beal et al., 2005; Rothbard \& Wilk, 2011) and was pointed out that the employees work performance and the job satisfaction are largely being affected by the work related emotional reactions (as cited in Mukherjee \& Sreeja, 2018). Weiss and Cropanzano (1996) highlighted that the work related events need not to necessarily be more dramatic or enormous to activate an emotional reaction because sometimes the way that the employee react to a situation is also significant and the theory has not mentioned any specific restrictions on the types of the events in order to activate the emotional responses. But studies have indicated that the emotional contagion emphasized the importance of the emotional displays of a leader in activating the stimulus (as cited in Mukherjee \& Sreeja, 2018).

\section{Association between Emotional Contagion and Individual Work Performance}

It was indicated that the emotions displayed at work can have a direct impact on the employees work performance (Mukherjee \& Sreeja, 2018). Barsade (2002) experimentally proved that the positive emotional contagion among the individuals will generate positive emotions and attitudes as if cooperativeness, less conflicts, and high level of tasks performance (as cited in Im, Park, \& Storey, 2013). It was mentioned that the existence of positive 
emotions considered being highly significant in enhancing the cognitive performance and general wellbeing (Forgas and George, 2001; Frederickson, 2003, as cited in Dasborough et al, 2009). Esmond-Kiger et al., (2006) indicated that the work related attitudes are being influenced by the emotions where Frost (2003) and Rothbard and Wilk (2011) mentioned that, when the negative emotions are spreading in a workplace, this will lead to reduce the work performance of the organization and it can have a negative impact on employees' work related attitudes. Because as pointed out by Hatfield, Cacioppo and Rapson (1994) emotions considered being contagious (as cited in Mukherjee and Sreeja, 2018). The impact of emotional contagion on employees' work attitude has been explored in relation to the service sector (Barsade et al, 2018). The individuals are influenced by the others' thoughts, attitudes, and their moods along with emotions when they interact with each other's that are in the same network and thus, it has been identified as critical social and organizational factor that make an impact towards the individuals' work related attitudes and affect their behaviors as if turnover (Felps et al., 2009, as cited in Im, Park, \& Storey, 2013). Work performance, work related attitudes, and work relationships have largely been influenced by the employees' emotions and this has taken the attention of the researchers in past decades (Rajah, Song and Aryey, 2011). Pugh (2001) indicated that the employees possess a direct influence on all the affective states of the stake holders in any organization (as cited in Mukherjee and Sreeja, 2018).

Accordingly, below two hypotheses were advanced in the current study to be tested with primary data, which is further depicted in Figure 02 conceptual framework of the study.

H1a: There is a significant relationship between emotional contagion and individual work performance of employees.

H1b: There is a significant impact of emotional contagion on the individual work performance of employees.

The conceptual framework depicted in figure 02 was developed assuming that other factors remain constant, in which emotional contagion is considered the independent variable and individual job performance is considered the dependent variable.

Figure 02: Conceptual Framework

Source: Authors, 2020 


\section{Research Methodology}

\section{Research Design}

The current study strives to test the advanced hypotheses and the established relationships in the research model. It is more accurate to identify the present study as an explanatory research. Moreover, it is significant to point out that there is no any clear-cut educational manifestation which conveying the relationship of the impact of the aforesaid two variables of emotional contagion and the work performance within the Sri Lankan context though the attention has been given to this field in other countries. Thus, it is imperative to test the relationship and the impact of these variables pertaining to the Sri Lankan context. Furthermore, the study has been carried out as a quantitative research work and in order to deliver more reliable information, descriptive statistics are used as if mean, mode, variation, and standard deviation. Correlation and the simple regression were computed in this study to obtain the results. The current study used both primary and secondary data in order to generate more accurate results. Primary data were collected by using the questionnaires and the secondary data has been used by referring the previous studies in journals, conference proceedings and the books. The questionnaire has been distributed after testing for the reliability and validity. Unit of analysis for the study is at the individual level; an employee who is in the age of 18 years or above who is working in the corporate sector in Sri Lanka.

\section{Population}

When it comes to the current study, the habitual nature of the employees of catching others' emotions who are in the workplace cannot be confined to a particular company or an industry as it is a common phenomenon for all the humans. Thus, the population concerned for the current study includes all the employees who are working in the organizations in Sri Lanka who are in the age category of 18 years or more than that where it is convenient with the current researcher. Hence, total number of elements in the population of the current study is unknown.

\section{Sample and the Sampling Technique}

Since the phenomenon of emotional contagion is a common characteristic that every human possess in nature, it is not logical to confine only to one particular industry, sector or to a particular sub-society as it is an open cross-society, cross-industry and crossregional concept. As the total number of respondents in the population is unknown to, the convenience sampling technique, which is a non-probability sampling technique, would be more appropriate to select the sample. The method has chosen based on personal judgment and convenience. According to Hair et al. (2010), a sample of 100 elements would be sufficient under convenient sampling for a research follows the quantitative approach. Thus, the sample was chosen at the convenience of the researchers, which consists of 100 respondents. 


\section{Measurement Scales of Variables}

\section{Emotional Contagion}

The construct 'emotional contagion' was assessed as a unidimensional variable adopting the 'Emotional Contagion Scale (ECS)' developed by Doherty (1997). Fifteen (15) items were used to measure the construct which were anchored on a five-point Likert scale as in the original scale. Sample items include: 'If someone I'm talking with begins to cry, I get teary-eyed'; 'I cry at sad movies'; 'Listening to the shrill screams of a terrified child in a dentist's waiting room makes me feel nervous'; 'When someone smiles warmly at me, I smile back and feel warm inside'.

\section{Individual Work Performance}

The dependent variable; individual work performance was assessed as a unidimensional construct using six (06) self-reported items, adopted from Kuvaas (2006). Respondents were asked to rate their level of agreement for the items on a five-point Likert scale anchored at $1=$ strongly disagree and $5=$ strongly agree. Sample items include: 'I almost always perform better than an acceptable level'; 'I often perform better than can be expected from me'; 'I often put in extra effort in my work'; 'Quality of my work is top-notch'.

\section{Data Collection and Analysis}

Survey questionnaire was adopted from the measurement scales of Doherty (1997) and Kuvaas (2006). It was administered to the respondents directly in on-line mode, as a google form. They were assured that the results would be reported in aggregate to ensure their anonymity. Moreover, one open-ended question was given at the end of the questionnaire to record other comments relating to emotional contagion and individual work performance. The collected primary data were analyzed with the aid of Statistical Package for Social Sciences (SPSS) employing descriptive statistics, correlation and simple regression.

\section{Analysis and Results}

\section{Sample Composition}

Out of 108 questionnaires distributed, 106 respondents returned the filled questionnaires. However, out of those, 06 responses were discarded. Only 100 fully completed responses were entered into SPSS, and check for missing values and outliers. The effective rate of response after discarding ineligible responses from the sample was $92.59 \%$. Composition of the study sample is depicted across three major demographic factors; gender, age and civil status, in Table 01.

\section{Table 01: Sample Composition} [N=100]

\begin{tabular}{|l|l|l|}
\hline \multirow{2}{*}{ Gender } & Male & $48.9 \%$ \\
\cline { 2 - 3 } Civil status & Female & $51.1 \%$ \\
\hline \multirow{5}{*}{ Age group } & Single & $85.9 \%$ \\
\cline { 2 - 3 } & Married & $14.1 \%$ \\
\hline & $\begin{array}{l}18 \text { years - } \\
25 \text { years }\end{array}$ & $56.5 \%$ \\
\cline { 2 - 3 } $\begin{array}{l}25 \text { years - } \\
\text { 35 years }\end{array}$ & $35.9 \%$ \\
\cline { 2 - 3 } $\begin{array}{l}35 \text { years - } \\
45 \text { years }\end{array}$ & $5.4 \%$ \\
\cline { 2 - 3 } & $\begin{array}{l}45 \text { years - } \\
55 \text { years }\end{array}$ & $1.1 \%$ \\
\cline { 2 - 3 } & $\begin{array}{l}\text { Above } 55 \\
\text { years }\end{array}$ & $1.1 \%$ \\
\hline
\end{tabular}

Source: Analysed data (2020) 


\section{Reliability and Validity}

To ensure the reliability of measurement scales, internal consistency statistics were used. As recommended by Nunnally (1978) and Lu et al., (2007) construct reliability was assessed using the Cronbach's Alpha coefficient. As shown in Table 02, Cronbach's Alpha values of both variables are greater than 0.7 indicating that the multi item scales are reliable, and all the items have played a significant role in conceptualizing the respective constructs.

\section{Table 02: Reliability Statistics}

\begin{tabular}{|l|c|c|}
\hline Variable & No. of Items & Cronbach's Alpha \\
\hline Emotional Contagion & 15 & 0.825 \\
\hline Individual Work Performance & 06 & 0.838 \\
\hline
\end{tabular}

Source: Analysed data (2020)

According to the validity statistics given in table 03, cumulative percentage of the Extraction Sums of Squared Loadings (ESSL Cum\%) of both variables are greater than $50 \%$, and the item Factor
Loading (FL) values are above the threshold limit of 0.7 as recommended by Hair et al, (2010). So that, statistically, the construct validity is ensured.

Table 03: Validity Statistics

\begin{tabular}{|l|c|c|c|c|}
\hline \multicolumn{1}{|c|}{ Variable } & $\begin{array}{c}\text { No. of } \\
\text { Items }\end{array}$ & $\begin{array}{c}\text { Lowest } \\
\text { FL }\end{array}$ & Highest FL & $\begin{array}{c}\text { ESSL } \\
\text { Cum\% }\end{array}$ \\
\hline Emotional Contagion & 15 & 0.712 & 0.911 & 63.92 \\
\hline $\begin{array}{l}\text { Individual Work } \\
\text { Performance }\end{array}$ & 06 & 0.726 & 0.934 & 59.31 \\
\hline
\end{tabular}

Source: Analysed data (2020)

Moreover, the primary data set was tested for basic two multivariate assumptions; normality and linearity. Based on the Skewness (-0.109) and Kurtosis (0.105) normality of the dependent variable was ensured. Further, building on the Sig. value (Sig. $=0.211$ ) of the deviation from linearity coefficient of ANOVA test a linear association was found between the dependent and independent variable. Hence, Pearson correlation coefficient was used to assess the strength of association among the said variables in the research model, as they are linearly correlated.

\section{Correlation Analysis}

Building on the linear relationship found among emotional contagion and individual work performance, Pearson Correlation Coefficient was used to assess the strength of association between the said two constructs. Further, Sig. (2-tailed) test was applied to test the 
Ekanayake \& Weerasinghe, KJHRM 2019, 14(02)

significance of the correlation

was non-directional. Results of the coefficient, as the advanced hypothesis correlation analysis are given in table 04 .

Table 04: Correlation Statistics

\begin{tabular}{|l|l|c|c|}
\hline & & $\begin{array}{l}\text { Emotional } \\
\text { Contagion }\end{array}$ & $\begin{array}{l}\text { Individual Work } \\
\text { Performance }\end{array}$ \\
\hline \multirow{4}{*}{$\begin{array}{l}\text { Emotional } \\
\text { Contagion }\end{array}$} & Pearson Correlation & 1 & $.397^{*}$ \\
\cline { 2 - 4 } & Sig. (2-tailed) & & 0.000 \\
\cline { 2 - 4 } & $\mathrm{N}$ & 100 & 100 \\
\hline
\end{tabular}

*. Correlation is significant at the 0.05 level (2-tailed).

Source: Analysed data (2020)

According table 04, the Pearson Correlation has recorded as 0.397 suggesting that there is a weak positive association between two variables. As the Sig. (2-tailed) value is less than 0.05 at $95 \%$ confident interval $[\mathrm{Sig} .=0.000]$, the obtained correlation of 0.397 is considered being statistically significant. Thus, H1a is accepted.

\section{Regression Analysis}

Linear regression analysis was conducted to test the hypothesis ( $\mathrm{H} 1 \mathrm{~b})$ advanced for the impact of emotional contagion on individual work performance of employees. Results of the test are given in table 05 .

According to the model summary statistics given in table 05 , the $\mathrm{R}$ square value is 0.157 , which means that the emotional contagion has a $15.7 \%$ of an impact on the individual work performance of employees. In addition, that R-square is significant (as the Sig. value of $\mathrm{R}$-square given in table 05 is less than 0.05) On the other hand, it also provides and insight about the rest of the factors other than emotional contagion that affect individual work performance. Considering the R-square value it can be stated that (100\%-15.7\%) $84.3 \%$ of an impact come from the factors other than emotional contagion. Hence, $\mathrm{H} 1 \mathrm{~b}$ is accepted evidencing that there is a statistically significant impact of emotional contagion on individual work performance of employees. Accordingly, the regression equation could be obtained as follows.

Table 05: Regression Statistics

\begin{tabular}{|l|l|}
\hline $\mathrm{R}$ & 0.397 \\
\hline R-Square & 0.157 \\
\hline Adjusted R-Square & 0.148 \\
\hline Standard Error & 0.43621 \\
\hline Observations (N) & 100 \\
\hline F & 16.823 \\
\hline Sig. & $.000^{\mathrm{b}}$ \\
\hline Regression & Linear \\
\hline Method & Enter \\
\hline
\end{tabular}

Note: (a) Dependent Variable:

Individual Work Performance; (b)

Predictors: (Constant), Emotional

Contagion

Source: Analysed data (2020) 


\section{Regression Equation:}

$\mathrm{Y}=\mathrm{mX}+\mathrm{C}$

Where; $Y=$ Individual Work

Performance and $X=$ Emotional

Contagion

\section{Individual Work Performance $=\mathbf{2 . 4 1}$ + 0.37 Emotional Contagion}

\section{Discussion}

It is obvious that the employees are considered being the life-blood for every organization that ensures the health at the workplace. Deploying the right talent under the right cost to the right position in order to get the maximum benefits from them should be the main focus of every organization in order to achieve the goals and objectives and every organization should focus on to nurture the employees' work performance which directly link with the organizational overall performance. There are number of factors should be considered by the companies that affect the employees' work performance and here the employees' emotions play a crucial role in shaping their work performance. As explained by Weiss and Cropanzano (1996), according to the Affective Events Theory, the emotional reactions of workers have a direct impact on the employees work performance and the work related emotions directly influence on the workers level of satisfaction (as cited in Mukherjee \& Sreeja, 2018). Previous studies have proven that the emotions can be transfer from a person to person whether it is a positive or negative. The receiver's emotional display will be affected by the sender's emotional display as a result. This emotional infection is known as emotional contagion which can be identified as a critical factor that affects the work performance of the employees. Thus, it is advisable for the managers to consider about this factor when managing their workers performance.

Most importantly, in a work setting, managers should use their understanding about the emotional and mood contagion in order to spread their own emotions in a positive way to enhance and to nurture the team performance and to reduce the absenteeism and turnover by managing their emotions in a positive way. Empirical evidence clearly emphasized that the leader's emotions will affect the followers emotions. According to Schaefer and Palanski (2013), there is a visible transitionof emotions happens between workers in an organizational context where it was confiemd that the emotional displays of a leader at work directly related to the work attitudes and the work performance of the employees (Schaefer \& Palanski, 2013). In case if a leader can demonstrate positive emotions, it will be a powerful tool to make positive attitudes and behaviors of the employees. Apart from that, the team leaders should use the negative mood contagion as well sometimes especially in a situation where the teams have to meet the deadlines with the competing teams in order to give an understanding about the negative consequences that the team will have to face if they fail to achieve the targets. But, such kind of negative mood contagion should be stopped within a short period of time.

Furthermore, in the situations in which the company gives the training programs for the workers, in order to make them internalize what the trainer strives to deliver, he should consider about his vocal feedbacks along with moods and emotional contagion. If the trainer does 
not use any facial expression and the variations in vocals and talking with a monotone, the audience will not be able to catch what the trainer wants to deliver effectively. But, if he uses lot of facial expressions along with gestures and postures, variations in his vocal tones, and using different moods, it will lead the audience to actively interact with the session and they will quickly interact what trainer says. Managers should consider more on their emotional displays especially the anger rather than joyful emotions as angry emotions will spread so quickly than the happy emotions. Thus, especially in a team meeting, discussion, or in a one-on-one with a business partner of with an employee, or with the supervisor, everyone should consider about their emotional and mood displays.

\section{Conclusion}

Employees are the key asset of any organization who assists to achieve the goals and objectives effectively and efficiently by contributing their maximum effort for their organization. Thus, their performance should be effectively and efficiently nurtured by controlling the factors affecting to the performance properly. Emotions play a crucial role in shaping the employees' work performance as they are transferring quickly among individuals, which is known as emotional contagion. The present study has found that the emotional contagion and the employees' work performance are being positive correlate with each other and the emotional contagion impacts on employees' work performance. The study has revealed a valuable insight about the concept of emotional contagion and how it impacts on employees' work performance with the results obtained after analysing the data gathered by suggesting effective recommendations. Thus, the present research study would be more beneficial for the entire business sector who utilize the humans in their operations and for all the individuals who make their contribution at work to effectively deal with others especially by managing their emotions and moods.

\section{Recommendations}

The current researchers would provide the recommendations at two levels.

\section{Organizational Level Recommendations}

As indicated by the literature, it is obvious that the team leaders', managers' and the supervisors' emotions and moods as being transferred quickly to the followers, and between the other team members. Keep this in mind; the present study suggests the companies to consider about following recommendations. Implement Train the trainer training sessions to nurture the internal trainers' presentations skills along with the way in which they have to use the proper gestures, postures, vocal tones, moods and the way they have to manage their emotions especially in front of an audience to make them internalize what the training programs aim to deliver. Employees including all the managers should be provided a better understanding about how to handle their emotions in a proper way especially when they work as a team in the organizational context by specific training programs about the emotional contagion. It is advisable for the managers to control their emotions in front of other in an effective way where they should focus on to produce only the 
favorable responses from others. Moreover, the team leaders should be given the specific training programs about the negative emotional contagion in terms of the uses, duration, and their consequences. Because as mentioned, sometimes to meet the deadline with the competitors rather than using the positive emotions, negative emotions will be more effective in letting know the employees about the negative consequences that the entire organization will suffer as a result of fail to meet the deadline. But, these emotional displays should be reduced within a short period of time.

\section{Individual Level Recommendations}

Individuals should have a proper understanding about the concept of emotional and mood contagion when working. Thus, knowing the consequences, they should display appropriate emotions to others. Individuals should first understand the people they are interact with and how they usually react and this will be useful when interacting with them. It is also recommended to the individuals to spend time more with the ones who boost the morale and it is also important to practice how effectively they can manage their emotions and moods with the ones who hurt the emotions and moods while keep putting down when working. It is also advisable for the individuals to nurture the emotional intelligence when working which assist us to control our emotions when working with others.

\section{Limitations}

First limitation is, the current researchers had to confine to a sample which consists of certain number of participants; which is 100 . Second limitation is even though there are a number of factors that affect the employees' work performance, the present study has considered only about the emotional contagion. It would have been more expressive if other factors also be considered. The study is quantitative in nature, where the individuals' thoughts and ideas could have been collected if the present study has followed the mixed method, which includes the qualitative method as well.

\section{Directions for Future Research}

The present study has considered only about the emotional contagion that affect the employees' work performance. Thus, it is suggesting considering more factors affecting the employees' work performance to have more expressive outcomes. As the present study has conducted as a quantitative approach, and it would be more effective if a study can be conducted by using the qualitative approach as well where the researcher would be able to obtain the employees' perceptions as well. Moreover, the emotional displays of individuals are directly linked with the neurological factors of the humans. Thus, the neurological aspect of emotional contagion also an important factor that needs to be considered by the future researches.

\section{References}

Barsade, S., Coutifaris, C., and Pillemer, J. (2018). Emotional contagion in organizational life. Research in Organizational Behavior, 1-16. 
Bispo, J. and Paiva, A. (2009). A Model for Emotional Contagion based on the Emotional Contagion Scale.

Coplan, A. (2006). Catching Characters' Emotions: Emotional Contagion Responses to Narrative Fiction Film. Film Studies, 26-38.

Dasborough, M. T., Ashkanasy, N. M., Tee, E. Y., and Herman, H. M. (2009). What goes around comes around: How meso-level negative emotional contagion can ultimately determine organizational attitudes toward leaders. The Leadership Quarterly, 571-585.

Dobre, O. L. (2013). Employee Motivation and Organizational Performance. Review of Applied Socio- Economic Research, 53-67.

Doherty, R. W. (1997). The Emotional Contagion Scale: A Measure of Individual Differences. lounal of Nonverbal Behavior, 131-154.

Elnaga, A., and Imran, A. (2013). The Effect of Training on Employee Performance. European Journal of Business and Management, 137-147.

Frimpong, A. D., and Agyekum, B. O. (2018). Motivational Strategies for Improving Performance and Productivity amongst Records Staff in Ghana. International Journal of Scientific and Engineering Research, 432-466.

Guo, X., Vogel, D., Zhang, X., and Cao, X. (2016). Exploring the influence of social media on employee work performance. Internet Research.

Hancock, J. T., Gee, K., Ciaccio, K., and Lin, J. M. (2008). I'm Sad You're Sad: Emotional Contagion in CMC, 295-298.

Hatfield, E., Bensman, L., Thornton, P. D., and Rapson, R. L. (2014). New Perspectives on Emotional Contagion: A Review of Classic and Recent Research on Facial Mimicry and Contagion. An International Journal on Personal Relationships, 159-179.

Hatfield, E., Rapson, R. L., and Le, Y. L. (2009). Emotional Contagion and Empathy. In J. Decety, and W. Ickes, The Social Neuroscience of Empathy, 1-269). London: A Bradford book.

Hennig-Thurau, T., Gremler, D. D., and Groth, M. (2015). Not All Smiles are Created Equal: How Employee-Customer Emotional Contagion Impacts Service Relationships. Journal of Marketing, 58-73.

Howard, D. J., and Gengler, C. (2001). Emotional Contagion Effects on Product Attitudes. Journal of Consumer Research, 189-201.

Huang, P., and Dai, C. (2010). The Impact of Emotional Contagion and Emotional Labor Perception on Employees' Service Performance. International Journal of Electronic Business Management, 68-79.

Im, G., Park, E. H., and Storey, V. C. (2013). The Effects of Cognitive and Emotional Contagion on Repurchase Intentions of Information Technology. Thirty Fourth International Conference on Information Systems, 1-17. 
Kelly, J. R., and Barsade, S. G. (2001). Mood and Emotions in Small Groups and Work Teams. Organizational Behavior and Human Decision Processes , 99130.

Kramera, A. D., Guillory, J. E., and Hancock, J. T. (2014). Experimental evidence of massive-scale emotional contagion through social networks, 1-5.

Kumari, P., and Sangwan, V. (2015). A Study on Impact of Resilience Capacity on Job Performance of Executives in the Pharmaceutical Industry. International Journal of Management and Social Sciences Research, 27-34.

McIntosh, D. N. (2006). Spontaneous facial mimicry, liking and emotional contagion. Polish Psychological Bulletin, 31-42.

Mukherjee, U., and Sreeja, T. (2018). Impact Of Leader Emotional Displays And Emotional Contagion at work in India: An In Class Experiential Activity. International Journal of Business and Management Invention, 67-73.

Nummenmaa, L., Hirvonen, J., Parkkola, R., and Hietanen, J. K. (2008). Is emotional contagion special? An fMRI study on neural systems for affective and cognitive empathy. NeuroImage, 571-580.

Pereira, G., Dimas, J., Prada, R., Santos, P. A., and Paiva, A. (2011). A Generic Emotional Contagion Computational Model, 256-266.

Pradhan, R. K., and Jena, L. K. (2018). Employee Performance at Workplace: Conceptual Model and Empirical. SAGE Publications, 1-17.

Pradhan, R. K., and Jena, L. K. (2017). Employee Performance at Workplace: Conceptual Model and Empirical Validation. Business Perspectives and Research, 69-85.

Schaefer, R. A., and Palanski, M. E. (2013). Emotional Contagion at Work: An InClass Experiential Activity. Journal of Management Education, 533-559.

Schwartz, T. (2012, 07 11). Emotional Contagion Can Take Down Your Whole Team. Retrieved from Harvard Business Review: https://hbr.org/2012/07/emotionalcontagion-can-ta.html

Shahzadi, I., Javed, A., Pirzada, S. S., Nasreen, N., and Khanam, F. (2014). Impact of Employee Motivation on Employee Performance. European Journal of Business and Management, 159-166.

Taherdoost, H. (2016). Sampling Methods in Research Methodology; How to Choose a Sampling Technique for Research. SSRN Electronic Journal, 18-27.

Tsai, J., Bowring, E., Marsella, S., and Tambe, M. (2011). Empirical Evaluation of Computational Emotional Contagion Models, 1-15.

Vijayalakshmi, V., and Bhattacharyya, S. (2011). Emotional Contagion and its Relevance to Individual Behavior and Organizational Processes: A Position Paper. J Bus Psychol, 1-12. 